\title{
Bridging the Gap between Adolescents and Adults: A Case Study on Experiences of Teenagers while using Social Networking Sites and their Willingness to Seek Adult Help
}

\author{
A.R. Mubarak \\ Senior Lecturer \\ Department of social work and \\ social planning \\ Flinders University \\ South Australia SA5000
}

\author{
Judy O'Sullivan \\ Coordinator - Relationship \\ violence No Way \\ GP Plus Marion \\ Oaklands Park SA 5046
}

\author{
Zoe Harrison \\ Peer Educator - Relationship \\ violence No way \\ GP Plus Marion \\ Oaklands Park SA 5046
}

\begin{abstract}
This paper explores the positive and negative experiences of adolescent users of social networking sites (SNS) and the level of adult support they receive to deal with the challenges related to the use of SNS. Data for this research were collected through focus groups comprising 192 male and female adolescents aged between 12 and 17 living in Adelaide, South Australia. The focus-group discussions revealed that young people enjoyed social networking for a variety of positive reasons; however they also encountered a wide range of issues associated with the ways that they, and others, make use of this technology. This study respondents indicated the presence of a gap existing between adolescents and adults and this gap needs to be urgently narrowed in order to enable adults to provide appropriate support and help to ensure that young people are safe when using SNS. Based on its findings the present study argues that more studies are needed in order to understand the interesting and complex experiences of teenagers while using SNS, the rules which teenagers apply while using the SNS, and how far these conventions differ from those set by adults; all of these are needed in order to reduce the gap that currently exists between young people and adults.
\end{abstract}

\section{General Terms}

Safe social networking; social issues, young safety, internet safety

\section{Keywords}

Social networking sites, adolescents, parents, teachers, adults

\section{INTRODUCTION}

Internet use by adolescents in Australia has seen an exponential rise in recent times mainly due to a rapid increase in the popularity of social networking sites (SNS). A combination of social networking online and the increased accessibility of the internet through smartphones have resulted in the expansion of internet use by all Australians - but particularly by young people. Adolescents have developed a 'ritualistic routine' of regularly and frequently checking their SNS sites through their smartphones, a routine which has resulted in social networking cumulatively occupying many hours each day. In 2008 it was estimated that social networking and other related online communication activities comprised 64 percent of young people's total internet use time (1). However, the researchers are not aware of any current data on the number of teenagers using SNS in Australia or the duration of their daily SNS usage.

Adolescent use of SNS has been widely researched in recent years. Some researchers consider that SNS offer valuable opportunities for young people to explore their social world. For example, quoting Erikson's view that adolescents seek conflict-free energy in a mutually-supportive psychosocial equilibrium; Williams and Merton (2) argue that online SNS provide an unrestricted laboratory setting for adolescent identity experimentation as they seek to understand how they fit into the world around them. Mazur (3) stated that certain risky behaviors demonstrated by teenagers on SNS may appear dangerous but that they serve as a forum for safe selfexpression by teenagers to prepare them for experimentation in the real world. At the same time there are a few researchbased observations which focus on the negative impacts of SNS on teenagers. Specifically, a major, and as yet unanswered, question is how teenagers are able to use their judgment to ensure their own safety in a virtual world when this often proves challenging even for mature adults. SNS are well known for posing a range of issues such as identity fraud (4), intrusion into people's private social space (5), stalking, harassment, and misuse of personal information available on SNS (6), and cyber bullying (7). These studies show that addressing such threatening issues is even more challenging for adolescents because their judgment is still underdeveloped. Research evidence indicates that teenagers are vulnerable to exploitation and abuse while using SNS $(8,9)$. Moreover, other studies predict that teenagers' preoccupation with SNS might significantly increase the time spent on this activity at the cost of other academic, physical, and social pursuits, resulting in stress and time management pressures (10). Vulnerability to opportunistic cyber bullying (11) and young people's engagement in risky behaviour while using SNS (12), among other concerns, have been raised in research literature in recent years. There are further concerns for teenagers regarding their gullibility and naivety when opening communication and when trustingly over-sharing their personal information through SNS; these issues have been debated by such research studies as Tow, Dell and Venable (13) and Hinduja and Patchin (14).

Due to the increasing concern regarding safety of adolescents while using the internet, researchers and policy makers around the globe have been researching on the ways in which adolescents can be helped to use the cyberspace safely (15). 
Parents as the primary caregivers of adolescents and their roles in safe use of internet by adolescents have been widely researched in recent years. These studies clearly highlight the existence of a wide gap between teenagers and their parents in relation to internet safety concerns. Mubarak (16) reported that only $10.6 \%$ of adolescents agreed that their parents took the initiative in guiding them regarding safe use of internet and this study also provided evidence that parents who had engaged in conversation with their teenage members of family regarding safe internet use managed to significantly reduce risky behaviours of teenagers online. However, Lenhart (15) observed that adolescent self-reports regarding parental supervision and guidance may not corroborate with that of parental reports. While $62 \%$ of parents reported that they checked up the websites their adolescent child visited, only $33 \%$ of their children reported that their parents checked up their online activity. Bjornstad and Ellingsen (17) observed that parents were alert to the online activities of their adolescent children as soon as the household got internet connection but in due course parental regulation disappeared once adolescents got used to using the internet. Livingstone and Bober (18) reported that while $86 \%$ of parents believed that they had advised their children not to divulge personal information with strangers online, only $49 \%$ of their adolescent children reported as not divulged personal information with strangers online. Tech-divide existing between teenagers and their parents has been reported as one of the contributing factors to the variations reported between parental and adolescent understanding of internet use. Bjornstad and Ellingsen (17) hypothesized that adolescents typically acquire internet competence much faster than their parents which might be a reason for parental overestimation of their supervision of adolescent child's online behaviours.

All these observations clearly highlight the obvious gap that exists between teenagers and adult carers in relation to safe use of the internet. However, these studies have focused on internet use of adolescents in general but not SNS in specific. Internet use in general is different from the use of SNS because SNS consumes much more teen time than general internet browsing and also SNS involves teenagers intensely communicating with many people increasing the possibility of them requiring more and frequent adult guidance and assistance. Since use of SNS being a new social trend, school and educational communities are still in the process of developing the definitive guidelines to monitor and educate members of the community and they are still in dilemma in many areas (19). Parents are also in a similar situation because many parents have just started using the SNS and there is an increasing concern among parents regarding safety of their adolescent children in SNS. Madden, et al., (20) conducted a national survey in the US and reported that $63 \%$ of parents of teens aged 12-13 years were concerned about safety of their child in SNS. This survey revealed that only less than half of the parents surveyed managed to take some actions to monitor and educate their teenage child in SNS. For example, only $39 \%$ of parents helped their teenage child to activate privacy settings in SNS. While this survey focused on parental perspective, the teen perspective is not known yet. To the knowledge of the researchers reliable data is not yet available regarding teen perceptions in seeking adult supervision and assistance to manage the issues arising from the use of SNS. Keeping this in view, the present study used a series of focus-group discussions with teenagers in order to collect information regarding their experiences while using the SNS and their level of preparedness to seek adult help and guidance to deal with issues related to the use of SNS. The observations of the researchers during the focus group discussions will be reported in this paper.

\section{RESEARCH METHODS 2.1. Participants and procedures}

The study participants were students aged $12-17$ years from Adelaide, South Australia and they were selected by means of purposive sampling. After obtaining the necessary ethics approvals, 10 schools located in Adelaide, South Australia were invited to participate in the project and among them three agreed to take part in the research. Seventeen focus-group discussions were conducted with a total of 192 students. The individual participants were selected by the schools according to their availability during the times allocated for the focus group discussions. All participants who took part in this research gained prior parental consent, the parents having been provided with a detailed description of the research and the topics. The discussion groups comprised mixed and single-sex groups as determined by the school. Peer educators facilitated the discussions after being specifically trained by researchers. All focus group discussions were of approximately 50 minutes duration and the discussions were audio-recorded. Each group covered the following topics for discussion:

- Positive and negative experiences of respondents while using SNS.

- Social issues relating to the use of SNS.

- Risks which young people take while using SNS and how those risks are managed.

- $\quad$ Sources of support (family, friends, etc.) available for young people to deal with the challenges relating to their use of SNS.

- Strategies adolescents use in order to respond to issues raising from the use of SNS.

\subsection{Data Analysis}

The audio-recordings of the discussions were transcribed verbatim by the researchers. Using Grounded Theory (21), the researchers separately coded all interviews and identified the major themes of the discussions of each group. The researchers reviewed their respective results after each coding process to ensure inter-coder reliability. The emphasis was on discovering dominant themes through comparison, clustering, labelling, and categorising. In this way a framework was constructed, giving order to the relationships between categories and the development of an overarching theory. Categories were perceived as 'saturated' when no new data emerged to challenge or alter the core category (22). The researchers repeatedly returned to the literature and drew from their lengthy experience of working in the area of child wellbeing to build a holistic understanding of the data and to reflect on the focus-group discussions.

\section{RESULTS}

Content analysis of the discussions revealed several major themes: positive and negative experiences while using SNS; risky experiences (their own and/or others') while using SNS; issues relating to teen use of SNS; legal repercussions of using SNS and personal and professional sources of help and support available for young people to deal with issues stemming from their use of SNS (Table 1). 


\subsection{Positive and negative experiences while using SNS}

Most commented that SNS had enabled them to remain in contact with friends from primary school, as articulated by one respondent: "you move school and you lose contact but then you find them on Facebook because everyone has Facebook". Social networking also allowed respondents to continue contact with family and friends who may have moved interstate or overseas. Another dominant theme regarding the benefits of SNS was that these facilities help young people stay in close contact outside of school hours. Members of the focus groups agreed that SNS helped them strengthen existing friendship networks and establish new friendships. Participants had long discussions on how socialising and entertaining had been made easy through the sharing of photos and how it had become possible to organise social events quickly and without difficulty. Importantly, the minimal cost and the uncomplicated use of SNS were perceived as big advantages for young people in rapidly widening their friendship networks. SNS such as Tumblr and Instagram were seen as forums for creative self-expression through photos and poetry, and they facilitated debates on topics of mutual interest with people who may be friends or strangers.

In regard to negative experiences associated with SNS, one central theme widely discussed was bullying; this, they commented, can take various forms such as rumour-spreading and the posting of rude or threatening messages on wall-posts. One respondent stated, "I've had my life threatened over Facebook". Another theme was that minor disagreements between individuals on SNS can result in major physical fights in school yards when the arguments escalate out of proportion. One respondent commented; "without social networking fights wouldn't happen as much". Use of various social networking forums to harass an individual by initiating manipulative and visible discussions about that particular individual - albeit without explicitly naming him/her - was a frequent occurrence. Present study respondents agreed that this is difficult to prove as harassment and yet it can cause serious psychological distress to the victim. One participant observed, "You'll see two girls that you don't like talking about you, but they don't say your name but you know it's about you. And then you'll retaliate, by making a status that's obviously talking about them and then it just goes back and forth". Another respondent stated; "It makes everything so much easier because you don't have to get the guts up to say it to their face, you can just type it behind the computer and you don't get the consequences as much"

\subsection{Social issues related to the use of SNS}

Participants made frequent reference to the use of location devices on smartphones and the 'tagging' of friends. The devices can be used by others to find the location of an individual, and this has apparently resulted in many embarrassing experiences. A few focus group members shared their experiences of providing false information about their location and subsequently being caught 'red handed' by parents, or fired by employers. Some participants expressed the view that modern technology was unhealthy and intrusive, particularly for young people who might need extra space to 'hide'; said one respondent, "I don't use the check-in thing. I don't really understand the check-in perk, why do you need to tell everyone where you are?" The sharing of personal photos was another popular topic that was discussed at length. They raised concerns regarding young people innocently and playfully sharing their personal photos on SNS, but in so doing they sometimes inadvertently divulged more information than intended, so revealing their whereabouts or inappropriate behaviour, such as underage drinking. Focusgroup members recalled many instances where photos posted on SNS had unanticipated negative consequences such as offending close friends and family members or projecting a poor image of the individual. This was noted to have caused negative employment outcomes as some employers had apparently used this as grounds for dismissal, and prospective employers used it as a justification for rejecting job applications. Many group members also shared their observations of adolescents posting photos or slanderous comments about their teachers or their school, thus leading to school suspension and the students being forced to remove the offensive material from his/her SNS.

Similar to this issue, many respondents shared their experiences of teenagers inadvertently publicising their personal information, such as phone number or address, to a wider audience due to their lack of knowledge of the SNS privacy settings or their naivety regarding the appropriateness of information posted in a particular manner. Teenagers trusting friends with their passwords and allowing friends to access their particular SNS were other topics which were frequently mentioned in the group conversations. Often the closeness of friendship is tested by an individual's willingness to share his/her password. This is particularly evident when teenagers are involved in intimate relationships, for it is considered that the sharing of passwords is crucial for building trust and confidence between partners. Unfortunately, when the friendship or relationship brakesdown ex-friends and ex-partners reportedly accessed the other person's SNS without permission in order to create trouble; for example, by spreading rumours about the ex-partner, by sending malicious messages, and by violating privacy.

\subsection{Risks young people take while using SNS and these risks are managed}

Focus-group members discussed the risks involved in sharing certain personal and sensitive information through SNS. For example, it was said to be common for teenagers to write about their mental health problems, often receiving inappropriate or damaging reactions from friends. The reactions may include hostile and ridiculing responses from online 'friends', behaviour which would not be expected in face-to-face encounters. Young people sharing disturbing visual content in SNS was also discussed in detail; this included posting photographic evidence of self-harm with captions such as, "Like this and I'll carve your name into my arm", or, "I did this because my girlfriend dumped me". (It must be noted that networking sites often remove inappropriate content if it is reported by other users). Many group members considered that sharing such self-harming and other risky behaviours is "too personal for SNS", some describing it as 'attention-seeking'. Focus-group members said that people interacting through SNS often showed extreme insensitivity to real problems shared by their 'friends' in SNS, tending to ignore or ridicule the person who shared the problems. However in spite of this reality, participants claimed that they could easily identify many examples of entire Tumblr profiles dedicated to glamorising self-harm. Group members shared their personal experiences of young people responding very inappropriately to personal problems shared by someone on SNS. It was generally agreed that even if someone shared extreme situations, such as the intention to commit suicide, and even if some sympathy for the individual were to be expressed, it was clear that social networking sites 
were viewed as unsafe for young people to share genuine and serious personal problems.

Fake SNS accounts was a common topic of concern. Recently Facebook announced that it had identified 83 million fake accounts. Participants of this research revealed that they frequently received 'friend' requests from suspicious sources, and they agreed that it is very common to see young people creating and using fake accounts to impersonate others. However, not all such uses are malevolent, respondents describing how some fake accounts are used to provide an alias for a few genuine purposes; for instance, to freely communicate with people who they were too shy to speak to; to ascertain whether their partner is faithful or straying, or to determine whether their friends were speaking badly about them behind their back. Even though most of the respondents expressed frustration at the existence of fake accounts, they described their own strategies for testing the validity of suspicious profiles, and they said that they readily rejected friendship requests deemed malicious.

\subsection{The group dynamics stemming from interactions with large list of friends}

While discussing the number of people listed as 'friends' on their SNS, participants expressed the belief that most adolescents have between 200 to 800 'friends', and the usual criterion for deciding whether to add someone as a 'friend' on Facebook was, "If I know them I'll accept them". However, group members had different opinions regarding what was meant by 'knowing' someone: some considered it necessary to meet a person several times before accepting the person as a friend whereas other members used SNS to commence new friendships with friends-of-friends, or acquaintances who they may have met once, briefly. One respondent stated, "but why do you have to know everyone? It's not like you're friends with them all, you just have them on Facebook". Another described using Facebook to turn an acquaintance into a friend: "So if you get along well and you're like "he's nice" and you add him and you talk to him a few times and then you see him at a party and you actually start becoming friends with him".

Many participants agreed that young people often consider the number of friends listed on SNS as a 'popularity contest'. This entails sharing personal observations of other young people, striving for a higher number of online 'friends', and placing strong emphasis on receiving attention in the form of 'likes' and comments on photos or statuses which they uploaded. One respondent described this phenomenon this way: "I guess it's very sort of subtle, because I don't hear people talking about how many friends they have but I think there is certainly a sort of sense of superiority if they do have a lot; they feel that lots of people pay attention to them, they feel important I guess".

While many young people are ambitious to win the SNS 'popularity contest' by having the highest number of online friends, at the other extreme is the danger of overdoing it. Some participants also cautioned about the prevalence of a subtle subjective difference between appearing popular on Facebook and being noted as a 'Facebook slut' who has 'too many' friends, thus prompting the assumption that one simply adds and accepts random users in order to appear very popular. It is evident that SNS have created a unique situation wherein young people are experiencing a peculiar form of peer pressure which may have significant impacts on an individual's public identity and sense of self-worth. On this issue, peer-pressure is intense; it is evident that young people are expected to participate in social networking (of 192 participants in 17 focus groups, only five individuals said that they had not started social networking, though they occasionally used mobile phones for text messaging); additionally, they are also expected to 'perform' and to present themselves as socially acceptable while remaining extremely cautious in their uses of SNS.

Table 1. Dominant themes emerged during focus group discussions and major topics covered under each theme

\begin{tabular}{|c|c|}
\hline Themes & $\begin{array}{l}\text { Major topics covered under each } \\
\text { theme }\end{array}$ \\
\hline $\begin{array}{c}\text { Benefits of } \\
\quad \text { SNS }\end{array}$ & $\begin{array}{l}\text { Keeping in contact with friends and family } \\
\text { despite physical distance; maintenance or } \\
\text { commencement of friendships; sharing } \\
\text { photos; organising events; free and easily } \\
\text { accessible; entertaining. }\end{array}$ \\
\hline $\begin{array}{l}\text { Challenges } \\
\text { while using } \\
\quad \text { SNS }\end{array}$ & $\begin{array}{l}\text { Cyber-bullying; organised fights; rumour- } \\
\text { spreading; sharing too much personal } \\
\text { information (eg. mental health issues), } \\
\text { embarrassing material (eg. photos, videos, } \\
\text { personal information) available in more } \\
\text { public/permanent format; employers or } \\
\text { parents becoming privy to private } \\
\text { information. }\end{array}$ \\
\hline $\begin{array}{l}\text { Risky } \\
\text { experiences } \\
\text { while using } \\
\quad \text { SNS }\end{array}$ & $\begin{array}{l}\text { Slanderous comments about } \\
\text { teachers/employers resulting in sanctions; } \\
\text { sharing too much information through } \\
\text { checking-in/tagging at certain locations; } \\
\text { misunderstanding/not using privacy } \\
\text { settings; inappropriate photos; divulging } \\
\text { personal issues online; fake accounts; } \\
\text { getting arrested/warned regarding } \\
\text { displaying inappropriate material though } \\
\text { SNS. }\end{array}$ \\
\hline $\begin{array}{l}\text { Issues with } \\
\text { family/friend } \\
\quad \text { s }\end{array}$ & $\begin{array}{l}\text { Many students had experienced issues with } \\
\text { family/friends due to information exposed } \\
\text { through social networking; using fake } \\
\text { accounts to determine friend/partner } \\
\text { fidelity. }\end{array}$ \\
\hline $\begin{array}{l}\text { Ability to } \\
\text { decline friend } \\
\text { requests }\end{array}$ & $\begin{array}{l}\text { Deleting friends or creating blocks/filters is } \\
\text { time-consuming; do routine culls (delete } \\
\text { people who are not friends); able to decline } \\
\text { "friend' requests that may be insincere or } \\
\text { suspicious; largely felt "If I know them I'll } \\
\text { accept them" (ie. having friends in common, } \\
\text { knowing of them, having met them on one } \\
\text { or more occasions); felt pressured to accept } \\
\text { unwanted requests from family members; } \\
\text { Comfortable blocking people with whom } \\
\text { had issues }\end{array}$ \\
\hline $\begin{array}{l}\text { Keeping } \\
\text { friends list } \\
\text { under control }\end{array}$ & $\begin{array}{l}\text { Generally, deleting friends or creating } \\
\text { blocks/filters seen as too much effort and } \\
\text { time-consuming, although some people do } \\
\text { routine 'culls' (i.e., deleting many 'friends' } \\
\text { all at once). Instead, young people may } \\
\text { monitor the personal information they share } \\
\text { online or delete an account and make a new } \\
\text { one with new criteria for accepting friends. } \\
\text { Young people do not feel pressured to } \\
\text { communicate with every SNS friend they } \\
\text { have. }\end{array}$ \\
\hline $\begin{array}{l}\text { Sources of } \\
\text { help and } \\
\text { support }\end{array}$ & $\begin{array}{l}\text { First will approach friends, older siblings } \\
\text { and lastly parents. School counsellors and } \\
\text { teachers untrustworthy unless issues were } \\
\text { specific to school; Police as last resort; }\end{array}$ \\
\hline
\end{tabular}




\begin{tabular}{|l|l|}
\hline & $\begin{array}{l}\text { focus group members unable to name } \\
\text { professional sources of support in their local } \\
\text { community. }\end{array}$ \\
\hline
\end{tabular}

\subsection{Sources of help and support in relation to the use of SNS}

When discussing about the sources of help and support teenagers received in relation to the use of SNS, the participants agreed that in spite of them experiencing the above mentioned demanding challenges, they will firstly approach friends and older siblings when they need any guidance and support. They will be reluctant to seek the help of adults. They will seek the help of parents only if the matter is serious. School counsellors and teachers were considered as untrustworthy because they reported the matters to parents without obtaining the consent of adolescents. One respondent stated, "I will seek the help of adults only to get into more troubles". When discussing about crisis situations due to problems related to SNS use, respondents mentioned police as only last resort. When the members of focus group discussions were asked to name a few professional sources of support available in their local communities, majority of focus group members did not know any such services available to their knowledge.

\section{DISCUSSION}

The focus-group discussions conducted for this research highlighted many important observations regarding the challenges adolescents experienced while using the SNS and at the same time lack of adequate adult guidance and help to deal with the challenges when needed. During the discussions participants repeatedly stressed that SNS are extremely pervasive and that they are not going away. The study samples asserted the view that while networking through SNS can be fun, it can also be hazardous if not used responsibly. Due to rapid advances in telecommunications technology, the users of SNS have apparently lost some traditional social boundaries, and adolescents were experiencing the pressure of constantly interacting with, and entertaining, the people around them - activities which can be tiring and very timeconsuming. While discussing the challenges which teenagers faced when using SNS, focus group members highlighted the apparent increase in the incidence of bullying, harassment, and rumour-spreading. One major observation that emerged from this enquiry is that bullying has become even more pervasive due to the constant use of SNS by adolescents, and it can have far reaching consequences. With the advent of smartphones children now have constant access to SNS and therefore may be bullied anywhere and at any time. Specifically, this study found that technology, such as tagging and location-finding facilities, has created an environment whereby bullying and harassment can be intensive, intrusive, and pervasive, so multiplying their negative impacts on teenagers. Due to the advances in technology and the rapid adoption of SNS by adolescents, there is an urgent need to identify better ways of helping young people deal with the new sources and forms of bullying and harassment. Engaging young people in self-reflection, raising awareness of the implications of irresponsible and damaging SNS use, and increasing the understanding and support from family members and teachers, are crucial ways in which young people can be empowered to use SNS in a safer manner.

Members of the focus groups also considered the many legal and other risks which teenagers take while using social networks. The discussions showed that while many young people were aware of the benefits of the security settings on SNS there seemed to be a lack of interest or urgency in using them. One student commented; "The security features can be useful to others particularly to the young ones but I am OK and I am capable of looking after myself". Many of the teenagers who participated in this research had clear ideas about the messages and materials appropriate for sharing through social networking, and there was general acknowledgement that, "if it's not suitable for your family to see, then it wouldn't be suitable at all, really". In spite of this realisation, participants of this research agreed that there is an increase in the incidence of hazardous behaviour such as sharing personal details with others on SNS and uploading potentially-harmful photos. The message that material uploaded to the internet will remain in cyberspace forever, in one form or another due to the complexity and vastness of cyberspace, was acknowledged by the groups, but it appears that the long-term implications of that message has not yet been understood by many participants of this research.

Social networking entails establishing close relationships with family, friends, and other members of the community. Traditionally, social networks were formed through personal contact and through the sharing of experiences and human emotions. Moreover, many studies have highlighted the links between participation in social networks and the wellbeing of individuals (23). Observations made during the present study showed that the participants presented a trend which was very different from the traditional understanding of the benefits of social networks. The focus groups expressed the view that social networks formed through SNS were ill-suited to offer psychological or social benefits to young people in distress. Often young people form social relationships on SNS without knowing each other well, and more importantly, it is done under peer pressure to have as many friends as possible. Specifically, it was evident from the comments and feelings expressed by the focus group members that teenagers who were already experiencing challenges, such as mental health problems and relationship issues, were vulnerable to insensitive and inappropriate interactions from social contacts formed on SNS.

Stress due to time management and 'performance pressure' was another topic discussed in detail by group members. In recent years young people have been pressured (often by their peers) to allocate more time for SNS, but this has been at the expense of other routine adolescent activities. While conducting the focus group discussions the researchers observed some partipants regularly checking and using their SNS while contributing to the conversations and some even used them in class when their teachers were present. An important observation of the present study is the phenomenon of teenagers struggling to establish a manageable balance between having too-few and too-many friends on SNS. While too-few 'friends' may imply that the teenager is unpopular, at the same time accepting too-many 'friends' suggests that the person is desperate and can even be branded as a 'slut'. The peer-pressure to perform well on SNS and the possible negative impacts on the social and psychological wellbeing of teenagers need to be further investigated by future research.

Another significant trend which the researchers observed during this enquiry was the sense that students were displaying 'cognitive disengagement' from the risks present on SNS and from learning how to avoid those risks. The partipants were able to articulate what they liked and disliked about SNS and they were very aware of the hazards which can come from SNS. But while demonstrating a high degree of awareness they were generally dismissive of the dangers, displaying an attitude of 'it is others people's problem and not 
mine'. This was evident when members expressed a deep concern about the safety of people younger than themselves, recognising an urgent need to impart information on the safe use of SNS to younger siblings or friends.

Taking into account all the interactions and views expressed by the members of the focus groups, the present research clearly highlights the challenges participants of this research experienced while using the SNS and an urgent need for guidance and assistance from adults. At the same time a dominant view voiced during the focus group discussions was that the adults present in the lives of study samples (including parents, teachers, and helping professionals) did not understand how SNS work and hence were unable to offer assistance when the teenagers encountered difficulties. Participants stated that many adult initiatives to protect children in their use of SNS entailed monitoring, restricting, or prohibiting the use of SNS. Indeed it was asserted that adults showed extreme insensitivity to the fact that SNS use was not controlled solely by the individual teenagers; rather it was determined largely by a complex arrangement of peer and other social and psychological influences. The participants of this research felt that adults need to realise that SNS as a social medium is important in the lives of young people and that despite the negative effects SNS use can be beneficial to teenagers in many ways. In recent years the awareness programs on cyber safety have focused on 'stranger danger' and cyber bullying, and behind these campaigns the agenda was to restrict teen use of the internet. Parents and other adults have been playing an indirect role by warning the teenagers about the risks without recognising the benefits for young people or the pervasiveness of SNS. The views expressed by the present study sample revealed that there is an urgent need for a change in this trend. It is important that adults involved in the lives of young people make an effort to initiate meaningful conversations with teenagers regarding their use of SNS. It is evident that many young people have had unhelpful experiences and that adults did not make an effort to initiate open conversation with the teenagers or to understand their experiences on SNS. This has ultimately deprived the adults of opportunities to strengthen their relationships with teenagers and guide them to use social networking in a safe and healthy manner. If adults were to develop a basic understanding of SNS and their uses it would help narrow the gap that currently exists between teenagers and adults. Only through such initiatives would it be possible for adults to understand the social world of their teenage children and to educate them to avoid such risky behaviour as using location devices without activating privacy settings, and sharing inappropriate or explicit photos and other material.

Present study suggests that:

- Adults show a greater interest in understanding the functions of SNS and familiarising themselves with the ways in which their teenage children use the sites. Take a genuine interest in the SNS young people are using and what they like about them.

- Adults make a conscious effort to maintain an open, non-judgemental dialogue with young people in order to find out what is important to them about social networking, who they are connecting with, how they decide which photos to put online, the style, level and frequency of information-sharing, and how to use location devices and tagging safely.

- When a young person approaches an adult to discuss an issue he/she is facing with regard to SNS, it is important that the adult should take this as a compliment and as a sign of trust. Listen to his/her experiences and provide support. Ask him/her what solutions he/she has thought of and what he/she would like the outcome to be.

- Adults need to be extremely cautious about suggesting that the young person should avoid using social networks or that the adolescent delete his/her online profile. It is important for adults to be conscious of the fact that online social networking is, at times, more important for the young person than face-to-face contact.

\section{CONCLUSION}

Young people continue to value their personal real-life relationships, and it can be argued that social networking strengthens face-to-face contacts and reinforces them by the instant sharing of personal experiences. Social networking is becoming embedded in young people's lives and it is imperative that the gap existing between adolescents and adults is narrowed in order to enable adults to provide appropriate support and help to ensure that young people are safe when using SNS. The issues that teenagers are experiencing (such as bullying, gossiping, and making poor choices) are not new; they are simply taking place at a faster pace and through a different, more public and permanent medium. As was evident in the dominant focus-group themes, young people enjoyed social networking for a variety of positive reasons, however they had encountered a wide range of issues associated with the ways that they, and others, made use of this technology. More studies are needed in order to understand the interesting and complex experiences of teenagers while using SNS, the rules which teenagers apply while using the SNS, and how far these conventions differ from those set by policy makers; all of these are needed in order to reduce the gap that currently exists between young people and adults.

\section{ACKNOWLEDGMENTS}

This research was sponsored by Flinders University's Southern Knowledge Exchange Grants. Our since sincere thanks to all the young people who participated in this research.

\section{REFERENCES}

[1] Australian Communications and Media Authority 2008 Media and communications in Australian families series No. 1, ACMA, Canberra, Australia.

[2] Williams, A.L., and Merten, M.J., 2008. A review of online social networking profiles by adolescents: Implications for future research and intervention, Adoles, 43 (170): 253 - 274.

[3] Mazur, E., 2005. Teen blogs as mines of adolescent data. Teach of psychol, 32 (3): $180-182$.

[4] Haddadi, H., and Hui, P., 2010. To add or not to add: Privacy and social honeypots, Proceedgins of the ICC 2010: International conference on communications 23 27 May, IEEE, Capetown, South Africa.

[5] Binder, J., Howes, a., and Sutcliffe, A., 2009 The problem of conflicting social spheres: effects of network structure on experienced tension in social network sites. In: Greenberg, S., Hudson, S.E., Hinckley, K., and Morris, M.R., eds. Proceedings of the $27^{\text {th }}$ Annual CHI 
conference on human factors in computing systems, 4 -9 April, 2009, ACM, Boston, USA.

[6] Gross, R., Acquisti, A., and Heinz Iii, H.J., 2005 Information revelation and privacy in online social networks (The Facebook case). In: De Capitani Di Vimercati, S., and Dingledine, R., eds. Proceedings of the 2005 ACM workshop on privacy in the electronic society, 5-7 November 2005, Alexandria, USA.

[7] Valkenburg, P.M., and Peter, J., 2009. Social consequences of the internet for adolescents: A decade of research, Current directions in psychol sc, 18 (1), 1-5.

[8] Lievens, E., 2011. Risk-reducing regulatory strategies for protecting minors in social networks, $\mathrm{J}$ of Pol, Reg and Strat for Telecom, Inform and Media, 13 (6): 43 - 54.

[9] Shirley, Chris, J., and Andy, P., 2007. Improving protection mechanism by understanding online risk, Inform Man and Comp Security, 15 (5): 382 - 393.

[10] Sharif, I., and Sargent, J.D., 2006. Association between television, movie, and video game exposure and school performance, Pediat, 118: 1061-1070.

[11] ARicak, T., Siyahhan, S., Uzunhasanoglu, A., Saribeyoglu, S., Ciplak, S., Ysmaz, N., and Memmedov, C., 2008. Cyberbullying among Turkish adolescents, Cyb Psychol \& Beh, 11 (3): 253 - 261.

[12] Hope, A., 2007. Risk taking, boundary performance and intentional school internet misuse, Discourse: Stud in the cult pol and edu, 28 (1): $87-99$.

[13] Tow, W.N., Dell, P., and Venable, J., 2010. Understanding information disclosure behaviour in Australian Facebook users, J of Inf Tech Res, 25: 126136.

[14] Hinduja, S., and Patchin, J.W., 2008. Personal information of adolescents on the internet: a quantitative content analysisof MySpace, J of Adol, 31 (1): 125 146.
[15] Lenhart, A. 2005 Protecting teens online. Washington, DC: Pew Internet \& American Life Project. Retrieved on August 18, 2014 from http://www.pewinternet.org/files/ old-media/Files/Reports/2005/PIP_Filters_Report.pdf.

[16] Mubarak, A.R., 2013. A theoretical framework on adolescents' risk-taking behaviours while using the internet in Australia, International $\mathbf{J}$ of tech, knowl and soc, 8: 8 (5): $27-37$.

[17] Bjornstad, T. L., \& Ellingsen, T. 2004 Onliners: A report about youth and the Internet. SAFT. Retrieved on August 18, 2014 from http://www.saftonline.org/On-Liners.

[18] Livingstone, S., \& Bober, M. 2004 UK Children Go Online: Surveying the experiences of young people and their parents. Downloaded on 18 Augsut, 2014 from http://eprints.lse.ac/uk/395/1/UKCGOsurveyreport.pdf.

[19] Foulger, T., Ewbank, A., Adam, K., and Popp, S., 2009. Moral spaces in Myspace: Preservice teachers' perspectives about ethical issue in social networking, $\mathrm{J}$ of tech in edu, 42 (1): 1-28.

[20] Madden, M., Cortesi, S., Gasser, U., Lenhart, A., and Duggan, M., 2012 Parents, teens and online privacy. Retrieved on 18 August 2014 from http://www.pewinternet.org/2012/11/20/ parents-teensand-online-privacy/

[21] Strauss, A., and Corbin, J. 1990 Basics of qualitative research: Grounded Theory procedures and techniques. London: Sage.

[22] Chenitz, W., and Swanson, J. 1986 From practice to Grounded Theory: Qualitative research in nursing. Menlo Park, California: Addison-Wesley.

[23] World Health Organisation 2007 Adolescents, social support and help seeking behaviour - An international literature review and program consultation with recommendations for action by Barker, G., World Health Organisation, Geneva, ISBN 9789241595711 . 